\title{
Optimal Techno-economic Sequence-based Set of Diagnostic Tests for Distribution Transformers Using Genetic Algorithm
}

\author{
Hamed Hashemi-Dezaki, Oleksandr Rubanenko², Maksym Hryshchuk², Olena Rubanenko \\ ${ }^{1}$ Regional Innovational Center for Electrical Engineering (RICE), Faculty of Electrical Engineering, University of West Bohemia \\ (UWB), 3061400 Pilsen, 26 Univerzitní, Czech Republic \\ 2 Department of Electrical Stations and Systems, Faculty of Electrical Engineering and Mechanics, Vinnytsia National Technical \\ University, 21000 Vinnytsia, 95 Khmel'nyts'ke Highway, Ukraine \\ * Corresponding author, e-mail: hhashemi@rice.zcu.cz
}

Received: 28 February 2020, Accepted: 01 April 2020, Published online: 10 September 2020

\begin{abstract}
The diagnostic measurement and tests of transformers are essential. Also, the costs of diagnostic tests are considerable. Hence, proposing a method to determine an economic-technical sequence-bases set of diagnostic tests for transformers is useful and interesting. In this paper, a new method is proposed to determine the optimal sequence-based set of diagnostic tests for distribution transformers. A new objective function based on the branch and bound concept is developed in this paper. The proposed optimization problem is solved by using the Genetic Algorithm (GA). The statistical data regarding the experimental diagnostic tests for more than 20 distribution transformers of South-West Power System Company (Pivdenno-Zakhidna Power System) located in Ukraine have been used. The usage of the actual statistical data of distribution transformers is one of the most important contributions of this paper. The comparison of the obtained optimum test results and those of a typical conventional non-optimum sequence of diagnostic tests illustrate the advantages of the proposed method. By applying the proposed method, it is achievable to perform the comprehensive diagnostic tests with the minimum required costs.
\end{abstract}

Keywords

distribution transformers, diagnostic tests, optimization, sequence-based set of tests, optimum economic-technical solution, Genetic Algorithm (GA)

\section{Introduction}

The power transformers are important elements in all parts of the power systems such as High Voltage (HV) transmission systems and Medium Voltage (MV) or Low Voltage (LV) distribution systems [1, 2]. The transformers are expensive, and it is interesting to decrease their manufacturing costs and increase their lifetime [3, 4]. The monitoring of power transformers to improve their lifetime has received a great deal of attention [5]. By implementing appropriate monitoring systems, it is possible to decrease the Loss Of Life (LOL) of power transformers and the corresponding costs [6]. Moreover, the power system reliability is dramatically affected due to transformer failures and interruptions [7].

The transformer operating condition monitoring is essential for reducing potential future failures and avoiding growing defects. It is important to develop an effective condition monitoring system, which can distinguish the transformer

condition as it changes. The studies show that if the small defects of transformers can not be detected, and they work under their non-healthy condition, the failures are steadily growing. These steadily growing defects lead to vital and critical damages. Hence, the major repairment and replacements cost would be significantly expensive [8].

Various diagnostic systems exist for transformers [9-11]. The developed diagnostic methods for transformers are divided into off-line and on-line methods $[12,13]$. Although the on-line diagnostic systems have different advantages, the off-line diagnostic systems are more practical, more accurate, and more accessible.

In this paper, the off-line diagnostic tests for distribution transformers are studied. Usually, it is necessary to perform a group of off-line diagnostic tests to decide that any transformer is under healthy condition or not. Then, some corrective and predictive actions should be performed based on 
the transformer condition. The performing of full diagnostic tests would be time-consuming and expensive. Also, there are numerous distribution transformers, and it is not possible to perform full diagnostic tests on all units.

In this paper, a novel methodology is proposed to make an appropriate techno-economic decision about the distribution transformer condition with the minimum required tests. The branch and bound method $[14,15]$ is used in the proposed method.

The proposed method is developed by using the off-line diagnostic test results of distribution transformers. Using the experimental diagnostic data for more than 20 distribution transformers of south-west power system company (Pivdenno-Zakhidna Power System) located in Ukraine is one of the most important contributions of this article.

The proposed optimization problem is solved by using the Genetic Algorithm (GA) to find the optimum sequencebased set of diagnostic tests for distribution transformers. The obtained optimum sequence-based sets of diagnostic tests are compared with other sequences to highlight the advantages of the proposed method. The results of the two examined methods are compared to illustrate the advantages of the proposed method.

\section{The faults and diagnostic solutions of distribution transformers}

In Table 1, the different types of distribution transformers faults $[16,17]$ have been presented. In addition, the probability of each fault type is shown.

The probability value of each fault type has been extracted from the historical and actual data of the southwest power system company (Pivdenno-Zakhidna Power System) in Ukraine.

In this paper, based on the data of the south-west power system company, following diagnostic tests and measurements have been considered for distribution transformers:

Table 1 The distribution transformer fault types and diagnostic solutions

\begin{tabular}{lccc}
\hline State & Fault Type & $\begin{array}{c}\text { Probability } \\
(\%)\end{array}$ & $\begin{array}{c}\text { Diagnostic } \\
\text { solutions }\end{array}$ \\
\hline$S_{1}$ & Turn-to-turn & 21 & $\pi_{4}, \pi_{5}, \pi_{8}$ \\
$S_{2}$ & Insulation problems & 2 & $\pi_{1}, \pi_{2}, \pi_{3}, \pi_{7}, \pi_{9}$ \\
$S_{3}$ & Fault to frame & 8 & $\pi_{1}, \pi_{2}, \pi_{3}, \pi_{7}, \pi_{9}$ \\
$S_{4}$ & Inter-turn short circuit & 6 & $\pi_{4}, \pi_{5}, \pi_{8}$ \\
$S_{5}$ & Opening of one or more & & $\pi_{1}, \pi_{3}, \pi_{4}, \pi_{5}, \pi_{8}$ \\
$S_{6}$ & parallel wires in the & 14 & $\pi_{1}, \pi_{6}$ \\
$S_{7}$ & Radial deformation of coils & 12 & $\pi_{1}, \pi_{6}$ \\
\hline
\end{tabular}

- Scenario $1\left(\pi_{1}\right)$ : Visual inspection of internal parts by opening the transformer tank [18];

- Scenario $2\left(\pi_{2}\right)$ : Dissipation factor $(\operatorname{tg} \delta)$ measurement [19];

- Scenario $3\left(\pi_{3}\right)$ : High voltage tests [20];

- Scenario $4\left(\pi_{4}\right)$ : DC resistance measurement of windings [21];

- Scenario $5\left(\pi_{5}\right)$ : Short circuit impedance $\left(Z_{k}\right)$ measurement [22];

- Scenario $6\left(\pi_{6}\right)$ : FRA analysis [23];

- Scenario $7\left(\pi_{7}\right)$ : Insulation resistance measurement [24];

- Scenario $8\left(\pi_{8}\right)$ : Transformer ratio test [25];

- Scenario $9\left(\pi_{0}\right)$ : Physical-chemical tests of transformer oil $[26,27]$.

There are other diagnostic tests for transformers, such as time-domain dielectric spectroscopy measurement [28], return voltage technique [29, 30], and Frequency Domain Spectroscopy (FDS) method [31]. It is possible to consider various diagnostic tests in the proposed method. However, in the south-west power system company (PivdennoZakhidna Power System) in Ukraine, the above-discussed 9 kinds of diagnostic tests are only applicable. Accordingly, the study of the usage of other diagnostic tests is considered as future work.

In Table 2, the costs of each diagnostic solution have been presented in Ukrainian hryvnia (UAH) based on the declared costs by the private laboratories.

The mentioned costs for performing different diagnostic measurement methods and scenarios could be normalized, too. The visual inspection of internal parts is the most expensive diagnostic solution, and the insulation resistance measurement is the cheapest solution, which their costs are $5000 \mathrm{UAH}$ and $250 \mathrm{UAH}$, respectively.

Table 2 The costs of diagnostic solutions

\begin{tabular}{lcc}
\hline Scenario & Diagnostic solutions & Cost (UAH) \\
\hline$\pi_{1}$ & $\begin{array}{c}\text { Visual inspection of internal parts by } \\
\text { opening the transformer tank }\end{array}$ & 5000 \\
$\pi_{2}$ & Dissipation factor $(\operatorname{tg} \delta$ ) measurement & 1000 \\
$\pi_{3}$ & High voltage test & 3000 \\
$\pi_{4}$ & DC resistance measurement of windings & 600 \\
$\pi_{5}$ & Short circuit impedance measurement & 1200 \\
$\pi_{6}$ & FRA analysis & 3000 \\
$\pi_{7}$ & Insulation resistance measurement & 250 \\
$\pi_{8}$ & Transformer ratio test & 700 \\
$\pi_{9}$ & Physical-chemical tests of transformer oil & 1100 \\
\hline
\end{tabular}




\section{Applied methodology}

In the proposed branch and bound-based method, a $n \times m$ matrix is defined for $n$ fault types and $m$ diagnostic methods. The introduced matrix determines each fault of transformers could be detected by which diagnostic methods. As can be seen in Eq. (1), the $i$-th row and the $j$-th element of the matrix would be 1 if the $i$-th fault type could be detected by the $j$-th diagnostic method:

$A_{i j}=\left\{\begin{array}{ll}1 & \begin{array}{l}\text { The } i \text {-th fault type could be detected } \\ \text { by the } j \text {-th diagnostic method. }\end{array} \\ 0 & \text { Otherwise. }\end{array}\right.$.

In this paper, it has been assumed that there are 7 fault types and 9 diagnostic methods. Hence, the dimension of the matrix $A$ would be $7 \times 9$. In Table 3 , the feasibility of any diagnostic method for detecting each fault type based on the discussed definitions has been demonstrated.

In the proposed method, the best techno-economic sequence-based set of diagnostic tests for distribution transformers is determined.

The branch and bound is one of the methods that would be useful for determining an appropriate set of decision variables [32-34]. The sequence-based set of diagnostic tests could be modeled based on the branch and bound method as Eqs. (2) to (4):

$$
\begin{aligned}
& T S=\left[T S_{1}, T S_{2}, \ldots, T S_{k}, \ldots, T S_{m}\right]_{1 \times m}, \\
& T S_{k} \in\left\{\pi_{1}, \pi_{2}, \ldots, \pi_{m}\right\}, \\
& T S_{i} \neq T S_{j} .
\end{aligned}
$$

The following rules are considered to determine the best set and sequence of diagnostic tests:

- The sequence-based set of diagnostic tests should detect all faults and defects comprehensively.

- The costs of diagnostic tests are independent of the tests sequence.

- By detecting the first fault or defect, the diagnostic tests are stopped.

Table 3 Diagnostic scenarios for different types of fault

\begin{tabular}{lccccccccc}
\hline & $\pi_{1}$ & $\pi_{2}$ & $\pi_{3}$ & $\pi_{4}$ & $\pi_{5}$ & $\pi_{6}$ & $\pi_{7}$ & $\pi_{8}$ & $\pi_{9}$ \\
\hline$S 1$ & 0 & 0 & 0 & 1 & 1 & 0 & 0 & 1 & 0 \\
$S 2$ & 1 & 1 & 1 & 0 & 0 & 0 & 1 & 0 & 1 \\
$S 3$ & 1 & 1 & 1 & 0 & 0 & 0 & 1 & 0 & 1 \\
$S 4$ & 0 & 0 & 0 & 1 & 1 & 0 & 0 & 1 & 0 \\
$S 5$ & 1 & 0 & 1 & 1 & 1 & 0 & 0 & 1 & 0 \\
$S 6$ & 1 & 0 & 0 & 0 & 0 & 1 & 0 & 0 & 0 \\
$S 7$ & 1 & 0 & 0 & 0 & 0 & 1 & 0 & 0 & 0 \\
\hline
\end{tabular}

A Boolean variable, as shown in Eq. (3), is defined to determine that the $k$-th diagnostic test could be useful for detecting the new eventual faults and defects in addition to the previous diagnostic tests:

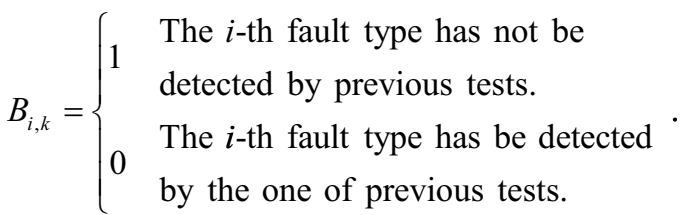

The Boolean variable shown in Eq. (5) could be determined by using Eq. (6):

$B_{i, k}=\prod_{\forall r \prec k}\left(1-A\left(i, T S_{r}\right)\right)$.

The cost and required budget for any sequence-based set of diagnostic tests could be calculated by using Eq. (7):

$T C=\sum_{k=1}^{m}\left[C_{k} \sum_{i=1}^{n}\left(A\left(i, T S_{k}\right) B_{i, k} P_{i}\right)\right]$.

In Eq. (7), the $T C, C_{k}$, and $P_{i}$ represent the total cost of the sequence-bases set of diagnostic tests, the cost of $k$-th diagnostic test, and the probability of $i$-th fault type, respectively.

The use of meta-heuristic algorithms like Particle Swarm Optimization (PSO), Genetic Algorithm (GA) to solve the optimization problem is useful $[35,36]$. In this paper, the Genetic Algorithm (GA) is used to solve the optimization problem. By applying the GA in the proposed method, it is possible to determine the best sequencebased set of tests with the minimum costs, which guarantees the complete detection of any fault in the transformer.

\section{Test results}

The proposed objective function has been implemented in MATLAB. The optimization problem has been solved by using GA.

The obtained optimum sequence-based set of diagnostic tests for distribution transformers is presented in Table 4.

By applying the optimum sequence-bases set of tests as demonstrated in Table 4, it is possible to comprehensively all fault and defect types of transformers with 2217.5 UAH.

The convergence diagram of the optimization problem solving by using the GA has been shown in Fig. 1 .

As revealed by the obtained test results, it is appropriate to measure the DC resistance of windings. This discussed

Table 4 Optimum sequence-based set of diagnostic tests

\begin{tabular}{lccccccccc}
\hline & $T S_{1}$ & $T S_{2}$ & $T S_{3}$ & $T S_{4}$ & $T S_{5}$ & $T S_{6}$ & $T S_{7}$ & $T S_{8}$ & $T S_{9}$ \\
\hline $\begin{array}{l}\text { Diagnostic } \\
\text { solution }\end{array}$ & $\pi_{4}$ & $\pi_{7}$ & $\pi_{6}$ & $\pi_{8}$ & $\pi_{2}$ & $\pi_{9}$ & $\pi_{3}$ & $\pi_{5}$ & $\pi_{1}$ \\
\hline
\end{tabular}




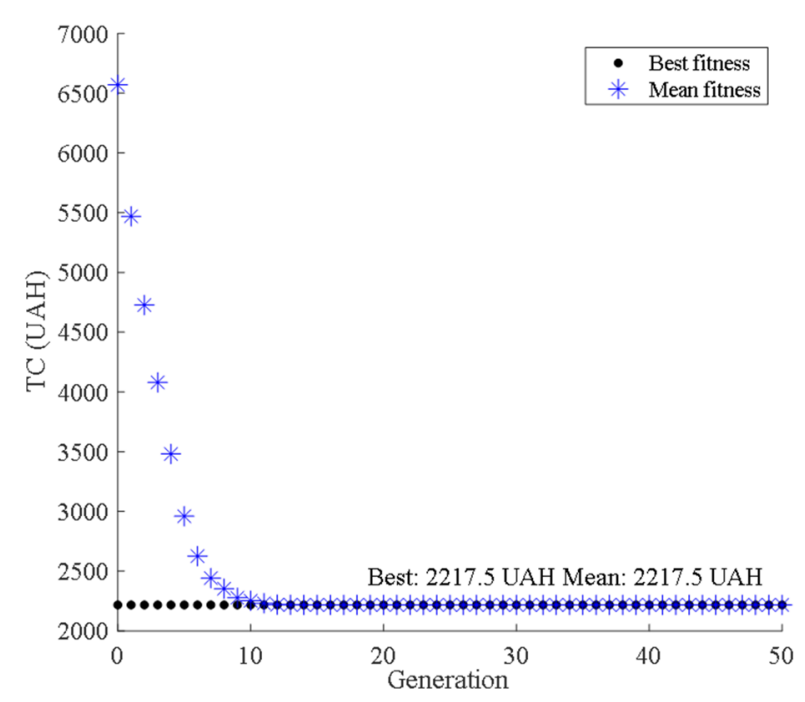

Fig. 1 The convergence diagram of solving the proposed optimization problem

test is not expensive. On the other hand, significant defects and faults could be determined by this measurement. The second recommended diagnostic test is the measurement of insulation resistance. By performing the insulation resistance, it is possible to monitor the insulation condition of the transformer. Since significant failures occur in the transformer because of the insulation weakness, this measurement is essential. Moreover, the FRA test, as the third recommended test, is useful to determine the mechanical condition of the transformer active part.

Although the considerable percentages of transformer faults are corresponding to the axial and radial deformations and could be detected by the FRA, it is better to perform this test after the DC resistance and insulation resistance measurements, as shown in Fig. 2. This is mainly because of the FRA test price.

After performing the FRA test, the other diagnostic tests could be useful to know more information about the transformer condition in details.

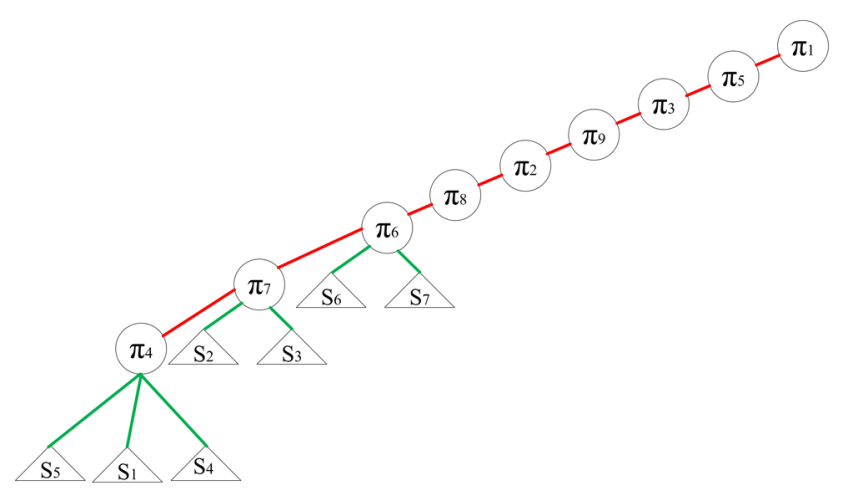

Fig. 2 The optimum sequence-based set of the diagnostic tests
The costs of other sets of diagnostic tests are compared to the obtained optimum test results to illustrate the advantages of the proposed method. For instance, the costs of the test set would be 10036 UAH, as shown in Table 5 and Fig. 3.

The comparison test results highlight that by applying the conventional non-optimum sequence of tests, the test costs would be increased about 5 times the optimum value.

\section{Conclusion}

In this paper, a new objective function has been proposed to determine the optimum technical-economic sequencebased set of diagnostic tests for transformers. The proposed optimization problem has been solved by using GA. By applying the proposed method, it is possible to perform the diagnostic tests with the minimum required costs while the comprehensive monitoring and diagnostic procedure have been achieved. The actual experimental diagnostic data and historical data for more than 20 PTs of southwest power system company (Pivdenno-Zakhidna Power System) located in Ukraine have been used to implement the proposed method. The use of the actual industrial data is one of the most important contributions of this paper.

The comparison test results showed that a typical conventional non-optimum set of diagnostic tests might lead to about a $500 \%$ increase in the costs of the tests. These obtained results illustrate the advantages of the proposed method.

Table 5 A typical conventional non-optimum sequence-based set of the diagnostic tests

\begin{tabular}{lccccccccc}
\hline & $T S_{1}$ & $T S_{2}$ & $T S_{3}$ & $T S_{4}$ & $T S_{5}$ & $T S_{6}$ & $T S_{7}$ & $T S_{8}$ & $T S_{9}$ \\
\hline $\begin{array}{l}\text { Diagnostic } \\
\text { solution }\end{array}$ & $\pi_{2}$ & $\pi_{3}$ & $\pi_{4}$ & $\pi_{5}$ & $\pi_{6}$ & $\pi_{7}$ & $\pi_{8}$ & $\pi_{9}$ & $\pi_{1}$ \\
\hline
\end{tabular}

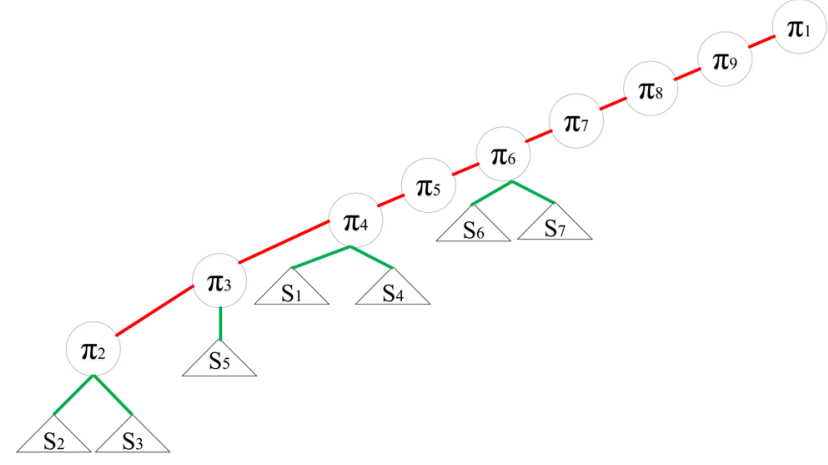

Fig. 3 A typical conventional non-optimum sequence-based set of the diagnostic tests 


\section{References}

[1] Shamlou, A., Feyzi, M. R., Behjat, V. "Interpretation of frequency response analysis of power transformer based on evidence theory", IET Generation, Transmission \& Distribution, 13(17), pp. 3879-3887, 2019.

https://doi.org/10.1049/iet-gtd.2019.0320

[2] Shanmugam, N., Madanmohan, B., Rajamani, R. "Influence of the Load on the Impulse Frequency Response Approach Based Diagnosis of Transformer's Inter-turn Short-Circuit", IEEE Access, 8, pp. 39454-39463, 2020.

https://doi.org/10.1109/ACCESS.2020.2976157

[3] Orosz, T., Tamus, Z. Á. "Non-linear Impact of the Short Circuit Impedance Selection on the Cost Optimized Power Transformer Design", Periodica Polytechnica Electrical Engineering and Computer Science, 2020. https://oi.org/10.3311/PPee.15331

[4] Orosz, T., Pánek, D., Karban, P. "FEM Based Preliminary Design Optimization in Case of Large Power Transformers", Applied Sciences, 10(4), Article Number: 1361, 2020. https://doi.org/10.3390/app10041361

[5] Zhang, F., Ji, S., Ma, H., Saha, T. K. "Operational Modal Analysis of Transformer Windings", IEEE Transactions on Power Delivery, Article Number: 19632817, 2019. https://doi.org/10.1109/TPWRD.2019.2939388

[6] Kumar, S., Kumar, L., Islam, T., Raina, K. K. "Condition Monitoring of Transformer Breather Using a Capacitive Moisture Sensor", IEEE Transactions on Industrial Electronics, pp. 9779-9789, 2019. https://doi.org/10.1109/TIE.2019.2952817

[7] Mousavi Agah, S. M., Hashemi, H., Azad, E., Nafisi, H., Safaie, A. "Effect of Distributed Generations on Aging Failure Probability of Distribution Transformers", Electric Power Components and Systems, 40(13), pp. 1470-1485, 2012. https://doi.org/10.1080/15325008.2012.700383

[8] Peharda, D., Ivanković, I., Jaman, N. "Using Data from SCADA for Centralized Transformer Monitoring Applications", Procedia Engineering, 202, pp. 65-75, 2017. https://doi.org/10.1016/j.proeng.2017.09.695

[9] Zhao, X., Yao, C., Li, C., Zhang, C., Dong, S., Abu-Siada, A., Liao, R. "Experimental evaluation of detecting power transformer internal faults using FRA polar plot and texture analysis", International Journal of Electrical Power \& Energy Systems, 108, pp. 1-8, 2019. https://doi.org/10.1016/j.ijepes.2018.12.045

[10] Fan, J., Fu, C., Yin, H., Wang, Y., Jiang, Q. "Power transformer condition assessment based on online monitor with SOFC chromatographic detector", International Journal of Electrical Power \& Energy Systems, 118, Article Number: 105805, 2020. https://doi.org/10.1016/j.ijepes.2019.105805

[11] Orosz, T., Sörés, P., Raisz, D., Tamus, Á. Z. "Analysis of the Green Power Transition on Optimal Power Transformer Designs", Periodica Polytechnica Electrical Engineering and Computer Science, 59(3), pp. 125-131, 2015. https://doi.org/10.3311/PPee. 8583
[12] Borges, G. B. C., Rohwedder, J. J. R., Bortoni, E. C. "Evaluation of the use of Near Infrared Spectroscopy (NIR) in on-line Monitoring of Power Transformer Insulation Oil", AASRI Procedia, 2, pp. 56-61, 2012.

https://doi.org/10.1016/j.aasri.2012.09.014

[13] Hejazi, M. A., Gharehpetian, G. B., Moradi, G., Alehosseini, H. A., Mohammadi, M. "Online monitoring of transformer winding axial displacement and its extent using scattering parameters and k-nearest neighbour method", IET Generation, Transmission \& Distribution, 5(8), pp. 824-832, 2011. https://doi.org/10.1049/iet-gtd.2010.0802

[14] Iria, J., Heleno, M., Cardoso, G. "Optimal sizing and placement of energy storage systems and on-load tap changer transformers in distribution networks", Applied Energy, 250, pp. 1147-1157, 2019. https://doi.org/10.1016/j.apenergy.2019.04.120

[15] Chenouard, R., El-Sehiemy, R. A. "An interval branch and bound global optimization algorithm for parameter estimation of three photovoltaic models", Energy Conversion and Management, 205, Article Number: 112400, 2020.

https://doi.org/10.1016/j.enconman.2019.112400

[16] Zhao, B., Yang, M., Diao, H. R., An, B., Zhao, Y. C., Zhang, Y. M. "A novel approach to transformer fault diagnosis using IDM and naive credal classifier", International Journal of Electrical Power \& Energy Systems, 105, pp. 846-855, 2019. https://doi.org/10.1016/j.ijepes.2018.09.029

[17] Aj, C., Salam, M. A., Rahman, Q. M., Wen, F., Ang, S. P., Voon, W. "Causes of transformer failures and diagnostic methods A review", Renewable and Sustainable Energy Reviews, 82(1), pp. 1442-1456, 2018. https://doi.org/10.1016/j.rser.2017.05.165

[18] Singh, J., Singh, S., Singh, A. "Distribution transformer failure modes, effects and criticality analysis (FMECA)", Engineering Failure Analysis, 99, pp. 180-191, 2019. https://doi.org/10.1016/j.engfailanal.2019.02.014

[19] Morsalin, S., Phung, T. B., Danikas, M., Mawad, D. "Diagnostic challenges in dielectric loss assessment and interpretation: a review", IET Science, Measurement \& Technology, 13(6), pp. 767-782, 2019. https://doi.org/10.1049/iet-smt.2018.5597

[20] Quan, Y., Ning, Z., Chen, S., Li, W., Xu, T. "Study on the methodology of detection for transformer winding insulation defects based on applied voltage test", In: 2012 IEEE International Symposium on Electrical Insulation, San Juan, PR, USA, 2012, pp. 153-155. https://doi.org/10.1109/ELINSL.2012.6251447

[21] Li, B., Guo, Y., Zhao, S. "Feasibility analysis of transformer winding DC resistance measuring on-line", In: 2012 International Conference on Systems and Informatics (ICSAI2012), Yantai, China, 2012, pp. 568-571. https://doi.org/10.1109/ICSAI.2012.6223061 
[22] Chiulan, T., Pantelimon, B. "A practical example of power transformer unit winding condition assessment by means of short-circuit impedance measurement", In: 2009 IEEE Bucharest PowerTech, Bucharest, Romania, 2009, pp. 1-4. https://doi.org/10.1109/PTC.2009.5282097

[23] IEEE "PC57.149/D9.2, IEEE Draft Guide for the Application and Interpretation of Frequency Response Analysis for Oil Immersed Transformers", IEEE, Washington, DC, USA, 2012.

[24] Notingher, P. V., Tanasescu, G. "Determination of Estimated, Consumed and Remaining Lifetimes of Paper - Oil Transformers Insulation Based on Winding Insulation Resistance", In: 2018 IEEE International Conference on High Voltage Engineering and Application (ICHVE), Athens, Greece, 2018, pp. 1-4. https://doi.org/10.1109/ICHVE.2018.8642211

[25] Iwanusiw, O. W., Eng, P. "The Art and Science of Transformer Ratio Measurement", In: 2018 IEEE Electrical Insulation Conference (EIC), San Antonio, TX, USA, 2018, pp. 390-394. https://doi.org/10.1109/EIC.2018.8481036

[26] Merritt, S. Y. "Anomalies in Interpretation of Transformer Oil Tests for Thermally Upgraded Paper-A Case History", IEEE Transactions on Industry Applications, 53(1), pp. 780-784, 2017. https://doi.org/10.1109/TIA.2016.2604301

[27] Orosz, T., Tamus, Z. Á. "Impact of the Cooling Equipment on the Key Design Parameters of a Core-Form Power Transformer", Journal of Electrical Engineering, 67(6), pp. 399-406, 2016. https://doi.org/10.1515/jee-2016-0058

[28] Mishra, D., Baral, A., Haque, N., Chakravorti, S. "Condition Assessment of Power Transformer Insulation Using Short Duration Time Domain Dielectric Spectroscopy Measurement Data", IEEE Transactions on Instrumentation and Measurement, Article Number: 19672802, 2019. https://doi.org/10.1109/TIM.2019.2947120

[29] Szirmai, Á., Tamus, Z. Á. "Modelling of dielectric processes in oil-paper insulation for replacement of Return Voltage Measurement", In: 2016 Conference on Diagnostics in Electrical Engineering (Diagnostika), Pilsen, Czech Republic, 2016, pp. 1-4. https://doi.org/10.1109/DIAGNOSTIKA.2016.7736490
[30] Tamus, Z. Á. "Combination of voltage response method with non-contact electrostatic voltage measurement to determine the dielectric response of insulating materials", Journal of Physics: Conference Series, 1322, Article Number: 012042, 2019. https://doi.org/10.1088/1742-6596/1322/1/012042

[31] Zhang, T., Li, X., Lv, H., Tan, X. "Parameter Identification and Calculation of Return Voltage Curve Based on FDS Data", IEEE Transactions on Applied Superconductivity, 24(5), Article Number: 9002405, 2014. https://doi.org/10.1109/TASC.2014.2344763

[32] Zhang, Z., Teng, L., Zhou, M., Wang, J., Wang, H. "Enhanced Branch-and-Bound Framework for a Class of Sequencing Problems", IEEE Transactions on Systems, Man, and Cybernetics: Systems, pp. 1-11, 2019. https://doi.org/10.1109/TSMC.2019.2916202

[33] Orosz, T., Sleisz, Á., Vajda, I. "Core-form transformer design optimization with branch and bound search and geometric programming", In: 2014 55th International Scientific Conference on Power and Electrical Engineering of Riga Technical University (RTUCON), Riga, Latvia, 2014, pp. 17-21. https://doi.org/10.1109/RTUCON.2014.6998194

[34] Orosz, T., Sleisz, Á., Tamus, Z. Á. "Metaheuristic Optimization Preliminary Design Process of Core-Form Autotransformers", IEEE Transactions on Magnetics, 52(4), pp. 1-10, 2016. https://doi.org/10.1109/TMAG.2015.2496905

[35] Orosz, T., Borbély, B., Tamus, Z. Á. "Performance Comparison of Multi Design Method and Meta-Heuristic Methods for Optimal Preliminary Design of Core-Form Power Transformers", Periodica Polytechnica Electrical Engineering and Computer Science, 61(1), pp. 69-76, 2017. https://doi.org/10.3311/PPee.10207

[36] Orosz, T., Tamus, Z. Á. "Impact of short-circuit impedance and tap changing method selection on the key-design parameters of core-form power transformers", Electrical Engineering, 100(3), pp. 1631-1637, 2018. https://doi.org/10.1007/s00202-017-0642-z 